\title{
WHO's in charge?
}

Global health remains firmly on the G8 agenda — for better or worse.

ast weekend's G8 summit in St Petersburg, Russia, may have been notable primarily for its state of paralysis over the latest crisis in the Middle East. However, behind the scenes, the meeting marked further progress in the group's assumption of responsibility for tackling global health problems. This attention is welcome - but the nature of the G8 forum and its exclusion of notable players, such as China, India and Brazil, carries risks.

Infectious diseases were one of the G8's top three declared priorities, alongside energy security and education, and the summit featured the first preparatory meeting of health ministers in the forum's thirty-year history.

A proposal to lure companies back into vaccine research by guaranteeing a market faltered, with Japan and Germany reportedly balking at the cost. But the meeting reiterated its support for financing the Global Fund To Fight AIDS, Tuberculosis and Malaria, and a host of other G8 health commitments, such as eradicating polio and making AIDS antiretrovirals available to all by 2010. There were no announcements of substantial new funding or initiatives, however.

Prompted by the world's failure to stop the spread of $\mathrm{H} 5 \mathrm{~N} 1$ avian flu, the meeting attempted to address the neglect of disease surveillance and emerging diseases (see Nature 440, 6-7; 2006). The spread of avian flu has exposed both the vulnerability of rich countries to diseases that emerge outside their own borders, and their lack of the vaccines or infrastructure needed to resist a human pandemic. In response, a G8 communiqué calls for better international cooperation on surveillance and monitoring, building infrastructure in affected countries, "full transparency by nations in sharing, on a timely basis, virus samples and other relevant information about the outbreaks of diseases" and "encouraging development of next generation influenza vaccines".

But this is just a wish-list, with no roadmap or funds - although the G8 reminded the world's countries that they should pay up the $\$ 1.9$ billion they pledged to the United Nations' avian-flu effort last January in Beijing, something most of them have yet to do.

Those who work in global health will, nonetheless, welcome the G8's explicit recognition of the importance of disease surveillance, and will hope that political attention at this level will ultimately pay off in the field.

Health issues have gradually grown in prominence at such summits, after AIDS and severe acute respiratory syndrome (SARS) reminded rich countries that they are not immune from emerging diseases. But tackling them requires far more resources than the G8 has so far managed to muster. And the attention of this elite group has had a side effect: the subtle shifting of money and influence away from the World Health Organization (WHO) and other UN programmes towards new organizations and government initiatives.

That shift may be no bad thing. The WHO is bureaucratic and sycophantic to its sovereign member states, and has a track record of failure in its programmes to tackle malaria and AIDS, although it fared better in handling smallpox and the 2002-2003 SARS outbreak. Like the UN Food and Agriculture Organization, which has taken a prominent role in the global response to avian flu, it is underfunded and chronically understaffed in key departments.

But the shift away from the WHO and other multilateral UN agencies carries risks. The G8 does not represent the world's people, and its members' national interests, including commercial ones, are not always aligned with global public health. A G14 or G20, including the leading developing countries, might do better in that regard.

Alongside the Global Fund and other G8 initiatives, the world's efforts to combat disease are also being transformed by privatesector initiatives, most notably those of the Bill and Melinda Gates Foundation, with its focus on late-stage product development.

But these efforts seem small and fragmented next to the challenges they are supposed to address. Future summits need to confront two major questions: how funding can be increased to levels that can do the job, and how, 58 years after the WHO's creation, the international community intends to agree and fund a coherent set of research and control priorities for global health.

\section{Safety catch}

\section{Risk assessment is a useful environmental tool, but not if it is used as a cover for a deregulatory agenda.}

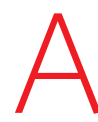
bulletin issued earlier this year by the White House Office of Management and Budget contains a number of recommendations on how the different parts of the US federal government should go about assessing risk (see page 242). The document, when it is finalized, will have an important bearing on how regulatory decisions such as environmental rules are made.

The topic of risk assessment sounds arcane but is of vital importance, especially to the United States' poorest communities. The poor have no say in setting the rules but bear the brunt of most environmental threats, including dirty water, polluted air and chemicals left behind on industrial sites. They will suffer the consequences if the balance of risk assessment is shifted in favour of the polluter. And if the current draft is implemented, that's exactly what will happen.

The United States has pioneered the use of quantitative risk assessments, which are now widely used around the world. The National Academies has played a central role in setting the agenda for how 